\title{
Overcoming Reluctance towards High Fidelity Simulation - A Mutual Challenge for Nursing Students' and Faculty Teachers
}

\author{
Marie Häggström ${ }^{1}$, Britt Bäckström ${ }^{1}$, Irene Vestling ${ }^{1}$, Karin Hallin ${ }^{1}$, Cecilia Segevall ${ }^{1} \&$ Lisbeth Kristiansen $^{1}$ \\ ${ }^{1 .}$ Department of Nursing science, Mid Sweden University, Sweden \\ Correspondence: Marie Häggström, Mid Sweden University, Department of Nursing Science, Holmgatan 10, \\ SE-85170 Sundsvall, Sweden. Tel: 46-70-142-866.
}

Received: March 16, 2017 Accepted: April 13, 2017 Online Published: April 18, 2017

doi:10.5539/gjhs.v9n7p127 URL: https://doi.org/10.5539/gjhs.v9n7p127

\begin{abstract}
Background: One strategy to develop nursing students' clinical judgment are the use of high-fidelity patient simulation (HFS). The aim of the study was twofold. Firstly, the aim of this study was to describe the nursing students' experiences while participating in HFS, and secondly to describe faculty teachers' reflections about nursing students' need in HFS and the related teaching challenges.

Method: Data was collected in focus group discussions and individual interviews, analyzed using thematic qualitative content analysis.

Findings: The nursing students' experienced HFS as being thrown into an uncertain, exposure situation. This were for some, reason for reluctance. The teachers challenge was motivating and coaching the students throughout a demanding teaching situation.

Discussion: Students' ability to perform in HFS is influenced by self-perceived efficacy, own attitudes and responsibility for one's learning, which are a challenge for the teachers.

Conclusion: HFS methodology can be useful to identify gaps and strengths in students' professional transition towards becoming registered nurses. Overcoming reluctance towards HFS is a mutual challenge for faculty teachers and nursing students. By entering the scenario with a positive mindset, nursing students can improve their ability to perform clinical judgments.
\end{abstract}

Keywords: clinical judgement, experiential learning, high fidelity simulation, nursing education, teaching perspective

\section{Introduction}

Studies show that newly qualified nurses find it difficult to transform theoretical knowledge into adequate care in complex clinical situations (Tanner, 2006) where patients' vital signs might be misinterpreted or mistreated leading to inadequate care (McCaughey, 2009). One challenge and a strategy to develop nursing students' clinical judgment may be through the systematic use of High-fidelity patient simulation (HFS) (Fitzgerald, 2012). Research on simulation has a long tradition, especially in North America. Despite this, today few Scandinavian studies have been focused on the challenges related to patient simulation in nursing education.

Clinical judgment is an interpretation or conclusion about a patient's needs, concerns, or health problems; and the decision to take action or not, use or modify standard approaches, or improvise new ones as deemed appropriate by the patient's response (Tanner, 2006). Training clinical skills is a crucial part of the nursing curriculum. Lack of training may lead to anxiety, worry, and speculation about professional nursing competence (Reid-Searl, Happell, Vieth, \& Eaton, 2012). There is a need for a variety of teaching methods to facilitate students' learning regarding the ability to correctly perform clinical judgments (Gates, Parr, \& Hughen, 2012), even though a study of Hallin, Häggström, Bäckström, and Kristiansen (2016, B) showed that a majority of the nursing students modelled a flexible learning style. HFS is defined as a technology that interactively replaces or enhances real-life events (Levett-Jones, Lapkin, Hoffman, Arthur, \& Roche, 2011) that offers varying degrees and methods with the potential to promote students' cognitive, associative, and psychomotor abilities in a patient-safe and realistic environment (Wotton, Davis, Button, \& Kelton, 2010). Nursing students at bachelor level need the opportunity to operate in a variety of complex simulated situations to develop required competencies. According to Taplay, Jack, Baxter, Kevin and Lynn (2014), nursing educators should implement 
simulation as a teaching strategy into nursing curricula. HFS enables nursing students to achieve clinical competencies (Waldner \& Olson, 2007), and get instant answers to their interventions (Gates, Parr, \& Hughen, 2012). HFS is proven to be an appreciated method for learning when compared to traditional classroom education (Garrett, MacPhee, \& Jackson, 2010; Garrett, MacPhee, \& Jackson, 2011; Guhde, 2010; Traynor, Gallagher, Martin, \& Smyth, 2010).

\subsection{Theoretical Perspective on Learning}

Learning is best conceived as a process based on reflection upon earlier experiences to be integrated into a new, deeper understanding whereby knowledge and problem solving are created through the transformation of experience (McCutcheon \& Pincombe, 2001). The theoretical framework for this study is the experiential learning theory (ELT) based on the "learning by doing" concept. According to Kolb (1984), ELT has a holistic, integrative perspective on learning and combines experiences and perceptions, cognitions, behaviors, and the person's internal motivation and interest. Experiential learning requires practical real-life situations through meetings with patients and discussions with colleagues where events and expressions are processed and reflected upon (Pilhammar, 2011). Observation and reflection on experiences from many perspectives is required as is the ability to create and integrate concepts into logically sound theories. Later, these theories must be used to make decisions and solve problems (Kolb, 1984). Thus, experiential learning emphasizes the importance of reflection in linking theory with practice and practice with theory (Kolb, 1984; Passarelli \& Kolb, 2011; Passarelli \& Kolb, 2012). However, the quality of the reflection is of greater significance to the learning outcomes than is the nature of experience itself (Andresen, Boud, \& Cohen, 2000). A central point in the construction of ELT is that the person experienced something that "stood out" from ordinary events (Pilhammar, 2011).

There is a need for evaluation research to help understand the impact of simulation, and to know what the learning outcomes are. Further, a Swedish study showed that last semester bachelor nursing students $(\mathrm{n}=174)$ underperformed in their clinical judgement (Hallin, Bäckström, Häggström, \& Kristiansen, 2016, A), measured by Swedish Lasater Clinical Judgment Rubric (Kristiansen, Häggström, Hallin, Andersson \& Bäckström, 2015). For this reason, nursing education must be improved.

In order for nursing education faculty to provide a sustainable experiential based learning environment, it is necessary to illuminate nursing students' experiences of HFS. To contextualize and to conceptualize the knowledge there is also a need for the nursing educators to make sense of student related findings and the related challenges, wherefore this study also aims to approach experienced teachers as well. The aim of the study was twofold. Firstly, the aim of this study was to describe the nursing students' experiences while participating in HFS, and secondly to describe faculty teachers' reflections about nursing students' need in HFS and the related teaching challenges.

\section{Method}

\subsection{Design}

The design of this study engaged an inductive qualitative approach. Latent content analysis was chosen to identify patterns and themes in variations in experiences from a learning and a teaching perspective (Graneheim \& Lundman, 2004). This study is a part of a larger project entitled "Values and Effects of High-fidelity simulation for the development of clinical judgment." To answer the aim for this study a qualitative design was selected as appropriate (Patton, 2002).

\subsection{Participants and Settings}

\subsubsection{The Student Sample}

The present study was conducted at two campuses at one university in Sweden. All students $(n=242)$ in the sixth (last) semester of the Bachelor of Nursing Science program took part in a compulsory HFS for their first time. Simulation was a common part in the curriculum. All students' (who attended the last semester), were asked to participate in the study. Of these students' were 30 interested, and had the opportunity to participate at the predetermined occasions that were given. Six men and 24 women $(n=30)$ aged 21 to 42 (median age 24) participated in the study. Prior to the nursing education, 25 students had experiences of primary care and/or caring for patients at hospitals, whereas, five students did not. Four students were assistant nurses, and one had practiced care HFS, but not during the current nursing education.

\subsubsection{The Teacher Sample}

As a part of the University's strategic work to enhanced sustainability and attractively to bachelor and advanced levels educations, 14 faculty teachers in nursing were engaged in special trained and educated as HFS facilitators 
and operators during 2011. While, after completing the student related study part, five nursing faculty teachers (two men and three women) from the same university institution were invited to reflect on the student related findings. The five teachers were selected mainly on the basis that these were the most experienced of HFS, purposively selected due to their profound knowledge and experience of HSF in nursing education. Except from one, the teachers were all registered nurses with more than 15 years of clinical nursing experiences, special education in university teaching, and between 8-20 years teaching experiences. Taken together they were well acquainted with both the teaching students and the HFS methodology.

\subsection{Settings}

The simulation scenarios, created by the clinical teachers, were designed to train clinical judgment skills in nursing, and took place at a clinical training center in an experimental hospital environment or at campus in special equipped simulation rooms. During each scenario the "patient" had nausea, vomiting, and difficulty breathing and hemodynamic instability. Before the simulation, the student were acquainted with SimMan and the expected learning outcomes were communicated. The students' preparation, and construction, and monitoring of HFS scenarios followed proven recommendations (Dieckmann, Gaba, \& Rall, 2007; Nehring \& Lashley, 2010). The simulator was controlled by an operator in an adjacent room. The students were divided into groups of 6-8 six-eight students, where half of them were actors and the others were observers interchangeable. The actors (the students) formed a care team where one of them took responsibility as a charge nurse while the observers noted action and communication skills. Each scenario lasted 10-15 minutes followed by 15-20 minutes of debriefing.

\subsection{Data Collection}

\subsubsection{First Data Collection}

The student related findings are based on data from six focus group (FG) discussions conducted two months after the HFS scenarios (by BB, KH, MH and LK), and two weeks before graduating. Each FG had between three to six informants that had agreed to participate. In accordance with Krueger and Casey (2000), the authors served as moderator and assistant moderator leading the discussions that lasted 60-90 minutes. Data was generated by addressing an overall question: "How did you experience the simulation?" Depending on how the discussion progressed, different follow up questions were asked. The interviews were digital recorded and transcribed verbatim.

\subsubsection{Second Data Collection}

The teachers were presented and asked to reflect upon student related findings with preliminary figures and tables with the emphasis on elaborating their perception on how findings may challenge the teaching. This was done in the form of one FG discussion (with three participants at one campus), and two individual interviews (at the other campus by IW and LK). The interviews lasted approximately one and half hour each. In similarity to the students' interviews, all were face-to-face, digital tape-recorded and transcribed verbatim.

\subsection{Analysis}

The interviews were analyzed using qualitative content analysis, the method is used to discover patterns, similarities, and differences sorted into sub-themes and themes (Patton, 2002). All transcribed FG as well as the two individual interviews data were read several times by the authors to get an overall picture of the content. With inspiration from Graneheim and Lundman (2004) the areas corresponding to the aim of this study were divided into meaning units, condensed close to the text, and labeled with codes. During the second part of the study, separate though, related teacher themes were generated, by asking the teacher data how they met the challenge shown in the three themes.

\subsection{Ethical Considerations}

After receiving oral and written study information, all participants gave informed consent about the study and were assured of confidentiality. None of the authors was the examining teacher for the recruited students, and therefore no dependence relationship existed. Mid Sweden University Research Ethics Committee's review (2012/499) declared no objections to the research.

\section{Findings}

The findings consisted of two overall themes mirroring the sense of central patterns from either perspective. The nursing students' experienced HFS being thrown into an uncertain, exposure situation, which sometimes were reasons for resistance. The teachers expressed that their challenges during HFS were motivating students throughout a challenging situation. The findings from the students and the teacher's samples, are presented 
below (see Table 1).

The student related finding are further abstracted in three themes and six subthemes: the nursing students expressed that they were facing something unknown, seeking courage and ability to enter into, and struggling with decision-making and diagnostic reasoning. The three themes illuminated how the nursing students performed in an uncertain exposure situation and described their feelings throughout their first simulation. Some expressed that the learning situation was a push forward for them and a wakeup call for the demands related to their upcoming nursing profession.

While, the teachers expressed that motivating the students throughout a demanding teaching situation also included to create a climate that contributed to learning. The teachers challenges were further presented in three themes; focusing the learning outcome, justifying training complexity and identifying strength and gaps. One informant expressed:

"Learning cannot take place unless one is safe. Then, safety do not include that I (the student) know exactly what will happen and how I (the student) should act and do during the HFS...If we (the teachers) create a space of safety, we (the teachers) can also provide a ground, an atmosphere, an allowing learning culture. "

Table 1. An overview over the students related findings and the teachers' reflections about challenges, presented in themes and related subthemes

Students' perspective:

"Being thrown into an uncertain, exposure situation"

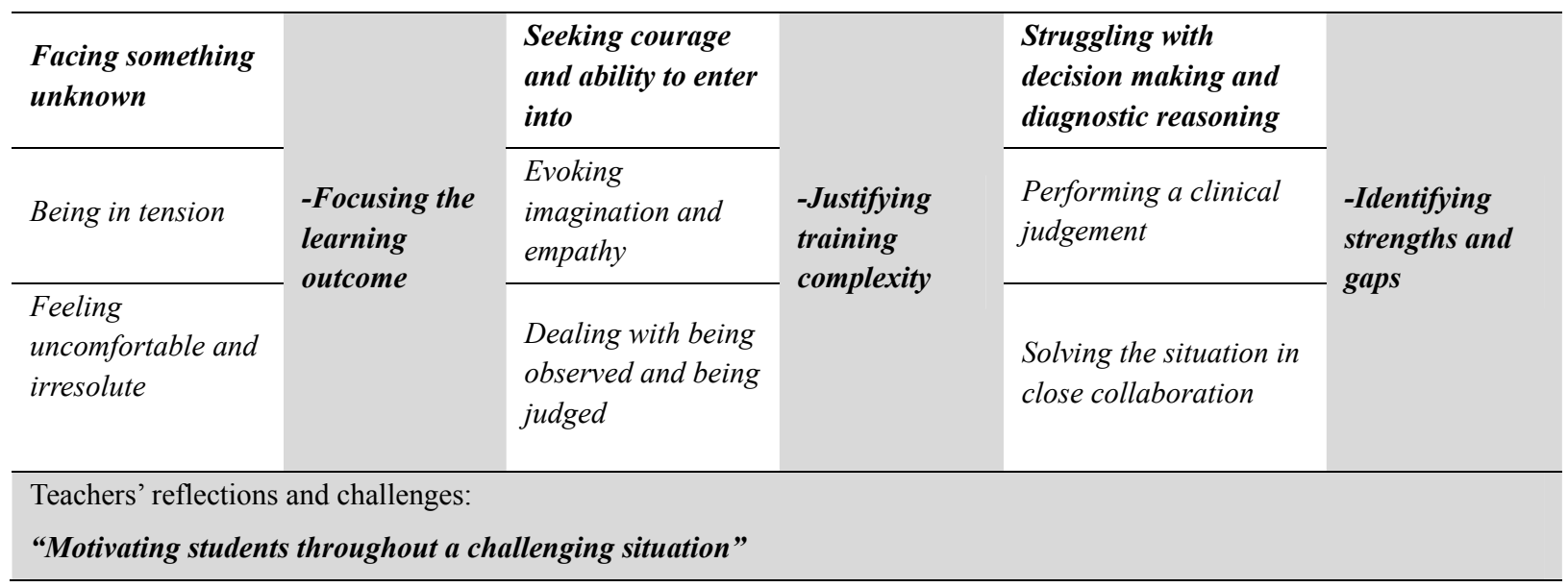

\section{Facing something unknown}

The theme, facing something unknown, is explained by the subthemes; being in tension and feeling uncomfortable and irresolute.

The students described being in tension waiting for something to happen. They knew that something would occur during the scenario, but not how and in what way. One FG:

"It felt like being thrown into something...//We waited and wondered what would happen, because we knew that something were about to start."

Despite the fact that the students previously had been trained in the environment, they searched for equipment and showed an uncertainty about these worked. They were feeling uncomfortable and irresolute. As the HFS was unfamiliar to the students, they were uncertain how to manage the manikin and the situation as such, and therefore the situation became confusing. Some expressed that SimMan was scary to face. Some described standing without a clear goal, which created negative feelings:

"I am unsure of what to do, how things work, where the things are. I was just spinning around ..." / / shall I just stand inactive and wait when I am confused? For how long shall I wait? Shall I wait until it (SimMan- the patient) even dies - or what?"

\section{Teachers reflections: Focusing on learning outcomes}

The teachers' perspective on facing something unknown, reflected a view where the students mainly were 
occupied with their own personal performance, rather than how they demonstrated their professional skills. This may be exemplified by the following teacher citation:

"It is remarkable when you see it like this (the student related findings) on paper, that it to a large extend refers to themselves as persons, and concerns their own experiences of what they themselves do and very little about the I/there is a little part of the figure //they have very little to say about the nursing task or the job itself I/they show difficulties to focus on the profession //they focus so much on themselves, which means that I, in this situation, regard them as very immature".

The teachers also thought about how to reduce the personal performance focus, in favor of focusing the learning situation. They reasoned that in order to being able to make the students feel safe, the teachers needed to work on reinforcing trust at a student level, for instance, by pointing out that HFS is a given opportunity to practice, and also to getting to know one's professional self. This challenge was often approached in way where as much transparency as possible was exposed. For instance the teachers, constantly focused on the learning outcomes in the curriculum, where they carefully and repeatedly informed student on the learning goal related to the HFS situation.

- "A warm and tolerant atmosphere is needed where we will add theoretical learning dimensions to the situation, and they (the students) also need to learn a lot about himself and his reactions. It's incredibly important who facilitate the scenario, and to have the qualification and an interest in this"

\section{Seeking courage and ability to enter into}

The theme seeking courage and ability to enter into is described in the subthemes evoking imagination and empathy and dealing with the observation and assessment situation.

The simulation situation with the manikin and the scenario were evoking imagination and empathy; many students were positive and showed enthusiasm for working with SimMan. The students who had the ability to enter the situation were amazed by the features SimMan displayed and reported a realistic experience. They expressed an "adrenaline high" and forgot time and space - it was just them and their "patient." The manikin became a real patient.

"... I felt that I went into some sort of bubble, and there was just me and the patient ..."

However, the students' experiences of their ability to enter into the situation differed. The lack of important human functions such as body language and facial expressions was perceived to be a barrier to entering into the situation. The students expressed that HFS gave them the opportunity to practice many important skills in a safe and secure environment. However, some expressed that it was a challenge to enter into the role of being a nurse and treating SimMan as a real patient. Some imagination made the SimMan and the scenario feel realistic.

"You're aware that there is a doll, but in my head it felt like a patient that can die if we do nothing."

The students felt that they had the opportunity to make any mistakes without injuring a real patient; the worst that could happen was that the exercise was stopped and restarted. The meeting was with a "patient" who could give feedback on the measures compared to just meeting an inanimate body part; this raised the caliber of the simulation engaging all senses. Many of the students felt that being observed during the simulation was uncomfortable and made them feel judged. They had trouble dealing with the observation and assessment situation and especially at the beginning of the simulation. Some students expressed a high level of stress because of the observers, and said that this affected their ability to enter into the situation. Other students meant that it was important to be observed because in the actual nursing environment it could be the patient's relatives watching.

\section{Teachers reflections: Justifying training complexity}

The teachers' perspective on seeking courage and ability to enter into showed that the students needed to be motivated to enter the scenario with empathy which is described in the theme justifying training complexity. Further, they expressed that it was important to emphasis the fact that becoming a nurse required overcoming own fears and to highlight that HFS were an opportunity to grasp the complexity in the work. The teachers often provided the students guts by telling that HFS contributed to a safe opportunity to learn by experience. Students also needed to be aware of that they, for example by relatives or physicians, would be observed in their professional role. It also became obvious for the teachers that some students had more hindrance overcoming being observed, than others.

//" they are not really competent handling being observed in this complex situations...// 
The teachers' reflections also showed that the students' individual reactions and the reflections toward the uncertain situation differed, and some seemed to have difficulty overcoming their confusion and uncertainty. During the HFS, some unsecure students got stuck in one specific task that they felt competent doing, which contributed to that their flow and team interaction were interrupted. From a teaching perspective it was a challenge to help students forward throughout the scenario. One teacher referred to how some students seem to think when they lose fluency and become stalled during the scenario;

"...I am counting the pulsations, so now for a moment, I feel safe standing here - only focusing on my task. I contribute with this specific task (counting patients pulsation), but in fact I'm disconnected from the group".

\section{Struggling with decision-making and diagnostic reasoning}

The third student theme, struggling with decision-making and diagnostic reasoning, is further explained by the subthemes; performing a clinical judgment and solving the situation in close collaboration.

It was a struggle to apply theoretical guidelines and performing a clinical judgment in the acute simulation situation. The students' minds were occupied interpreting the situation and the "patient's" condition. The learning objectives and assessment of vital signs were always visible in the HFS room. They felt that they did not know how to implement the theoretical knowledge, which was shown in the fact that they did not know how to interpret clinical signs or what the next step would be. Typically they got caught up in the clinical judgment, and not knowing what decision to make to proceed.

"Yes... You know what checks to do - but then you do not know how to continue ... and what to do when the vital signs are abnormal"

Knowing that nothing could threaten a real patient's life gave them the confidence to act and assume their assessments. After HFS, the students felt stronger and better prepared for their future professional role as a nurse. The findings showed how the situation gave a little glimpse of how the students might react in a real acute situation, and they learned more about their own preparedness and clinical competence. Disappointment in one's own performance was also described when they failed to make a relevant clinical assessment and did not know how to act in the simulation situation.

The students tried solving the situation in close collaboration by discussing different ways and various measures that could be taken within the team. A clear and effective team leader also gave the rest of the team a feeling of well-organized HFS. While, lacking a clear leader often ended in a chaos that caused inadequate "patient" treatment. Some students described that they became passive and just stood and waited for instructions from the team leader. The students believed that in a real situation, an experienced nurse would have to compensate and take the leadership role in similar situations. Besides, they understood that they in stressed and uncertain circumstances communicated poorly. One student experienced having received instructions from a team member five times, but because of the stress only heard the latest instruction:

"... It helps if someone talks clear, and provides feedback on what has been said, and perhaps talk a little loudly, so that everyone hears and knows what the situation is."

\section{Teachers reflections: Identifying gaps and strengths}

From a teaching perspective the student related findings found in the theme struggling with decision making and diagnostic reasoning were well recognized. The theme is contrasted by the teachers theme identifying gaps and strengths. They meant that HFS enabled them to observe student's levels of clinical skills. Initially, one teacher reflection was that in HFS it immediately was obvious whether the student were comfortable or not.

"...some students are scared to expose their lack of knowledge"

The student teams often approached the HFS with a positive fighting spirit were they wanted to systematically investigate the patients vital signs. If they monitored an irregular vital sign, they often forgot to fulfil measure the rest of the parameters in a complete clinical judgement. One issue was the students were preoccupied with medical diagnosing, instead of performing clinical judgements primary based on monitoring the vital signs and making sense of them, which lies within the profession of the nurse. During the debriefing, the important gaps and strengths were sorted out, discussed and were used as personal feedback that reinforced students learning. The teachers also saw the opportunities in having regular simulations following a progression towards feeling confident in the nursing role. The importance of good communication and teamwork described in the student findings was easy to confirm and also to evaluate. According to teachers, the students often were unaware of the own limits of knowledge and when to seek and ask for additional clinical help. The teachers reflected about the rich variation in skills, and how the student's personalities became a part of the learning environment and 
affected the performance.

\section{Discussion}

The aim of this study was to describe the nursing student experiences while participating in HFS, and further to describe faculty teachers' reflections about nursing students' need in HFS and the related teaching challenges. On an overall level, the nursing students' experienced HFS as being thrown into an uncertain, exposure situation. The finding shows a high degree of recognition from the side of the teachers. At no point they expressed surprise regarding the student-related findings. Rather they understood students' reactions and reflections and the faculty teachers' challenge are abstracted in the overall theme motivating students throughout a challenging situation.

For some, the HFS situations serve as a wakeup call for their upcoming roles as registered nurses and their clinical reasoning abilities. The transition from nursing student to professional nurse is described as a strained often difficult time; creating confusion among the expectant nurses with feelings of inadequacies (Pennbrant, Nilsson, Öhlén, \& Rudman, 2013). Facing something unknown, reflects the nursing students' tension and the uncomfortable feelings the situation caused. The teachers contrasted the student related findings on this matter, by focusing on the learning outcome. Different explanations are given for the confusion, such as fright of being observed, unaccustomed patient simulator, knowledge gaps or the team constellation. These findings is similar with the result in a recent study of Forslund Frykedal and Samuelsson (2017). Their study shows students' resistance participating in group work, and the reasons for resistance were blending, inability, stage frights, and vagueness. The students need to feel safe and to experience a positive learning environment with freedom to learn from mistakes and grow. The theme seeking courage and ability to enter into, highlights the need for imagination and empathy and how the nursing students need to deal with being observed and evaluated. Some students felt that HFS was a realistic and exciting exercise that served as a wakeup call that contributed to their learning. Others felt that interacting with a manikin was difficult and meant that this was unrealistic; this, combined with being observed, made them feel uncomfortable. The teachers interpreted their role as a coach providing guts and serve as a "reality check" during the scenario to overcome the fear, and contrasted with justifying training complexity. This is supported by Nielsen and Harder (2013) who also conclude that educators should be aware of possible causes of anxiety in order to moderate these levels. It is known that a student's ability to deal with new challenging situations can be influenced by the self-perceived efficacy and can be defined as the belief in their ability to organize and perform the correct actions (Leigh, 2008). Some nursing students expressed that the situation made them hesitant, tense up, and feel really insecure. Even if stress and anxiety mostly were mentioned as disturbing, we know that some level of stress may be beneficial Nielsen and Harder (2013). Lasater describes the paradox that even when students felt "stupid" and anxious during the scenario (Lasater, 2007), this is the kind of experience the students often learn the most from. Even though, newer research shows that students, overall, did not report either moderate or high stress associated with simulation, but they rated the HFS experience as a valuable learning tool (Cantrell, Meyer, \& Mosack, 2017)

Some studies show that simulation can increase self-confidence and contribute to the students feeling more prepared in clinical situations (Moreland, Lemieux, \& Myers, 2012). Our findings indicates that less confident students not appreciate the role of artificial playing, also seen by Henneman and Cunningham (2005), whom found that it took longer for less confident students to overcome the limitations of a patient simulator, compared with students who were more confident. Mould, White and Gallagher (2011) reported that students who were able to imagine a patient, instead of seeing the patient simulator, had an advantage in the interaction during the scenario. More exercises may increase the ability to empathize with the situation and interact with the patient simulator (Mould, White, \& Gallagher, 2011). This indicates that the ability to enter into can change over time and with practice.

Struggling with decision making and diagnostic reasoning shows how the nursing students tried to make decisions, perform diagnostic reasoning, and attempted to solve the situation in close collaboration. While, this was contrasted in the teachers' reflection identifying gaps and strengths. Both students and teachers expressed that HFS made them aware of the limitations in the clinical knowledge. This knowledge about gaps and strengths were valuable for the teacher and it was also obvious that students needed to train communication and leadership skills for a well-functioning team.

The findings of our study showed that HFS develop not only practical skills, but in the situation, the students become aware of their knowledge or lack of knowledge (Traynor et al., 2010). Therefore, it can be argued that HFS contributes to develop students' abilities to make decisions if the students are able to reflect on their efforts and learn from the situation. Besides, nursing students must feel committed and understand that the learning situation is worthwhile and important for contributing to their competence. A commitment that involves both 
theoretical knowledge and applying the mental energy required to overcome limitations, resistance and defense mechanisms (Illeris, 2013); also a challenge for the faculty teachers. Nonetheless, HFS contributed to a glimpse of reality using a scenario adjusted to the student's assumed level of knowledge. The findings are similar to other studies (Wotton et al., 2010; McCaughey \& Traynor, 2010), which also shows HFS as contributing to experiential learning.

This study illustrates that subjective factors such as individual motivation and attitude are of great importance for learning and affect the construction of their learning situation. Some may take all the challenges to learn and others do not. This may be due to the individual's approach to learning (Illeris, 2013), individual development, self-confidence, and belief in one's own ability to learn. This may also depend on personal responsibility for one's own learning; some students may even "expect to be spoon fed facts and procedures" (Devlin, 2002). This also illustrates that the experience and the simulation do not automatically generate learning. A theoretical and cognitive base is needed, and the students must have the necessary knowledge to be capable to identify, interpret, and reflect on the information provided in the situation (Ellstrom, 2001). We argue that the HFS methodology may serve an excellent opportunity for bachelor nursing students to use all senses; see many complex and various situations, develop intuition and clinical perspective; integrate theoretical knowledge into practice, and enhance personal and professional maturity.

\section{Methodological Considerations}

The choice of latent content analysis method was appropriate because the aim of the study was to elaborate experiences, perceptions, and patterns (Graneheim \& Lundman, 2004). After the first data collection with the students, we realized that the findings added no novelty regarding research contribution. Therefore, we re-designed the study and added the teachers' perspective, which in our opinion resulted in interested, useful findings especially for nursing educators. Besides, the interviews with the teacher's added the faculty perspective on the student related findings, which also can be seen as a validation of the result. The FG discussions were a suitable method to reach consensus and find out opinions, ideas, and thoughts on the specific topic (Krueger \& Casey, 2000). All interviews were conducted in an undisturbed environment at the University.

\subsection{Rigour/Trustworthiness}

This qualitative study are not aspiring to statistical generalizability, rather we aimed to reflect the diversity into a given population. In this study trustworthiness has been established with inspiration by Graneheim and Lundmans (2004) suggestions about trustworthiness in studies with qualitative content analyses (credibility, dependability and transferability). Credibility, meaning confidence in how well data and processes of analysis address the intended focus. This has been established by adequately addressing the aim with an appropriate sample selection and using quotations. Also, we have chosen participants with various experience which increases the possibility of shedding light on the research questions from a variety of aspects. Further, we have addressed credibility by the fact that we has worked as a whole in the research team and analyzed data in smaller constellation two and two. All studies risk that researchers may have missed certain information in interviews and analysis (Patton, 2002), but this should have been minimized in this study as the researchers, all RNs and educators, were familiar with the concepts and contexts. All parts of the analysis has been repeatedly worked through, and the most suitable meaning units were agreed upon within the team. Dependability (taking into account both factors of instability and design induced changes) was established by addressing the same initial questions in every interview. Finally, transferability has been established by adding a clear and distinct description of the context, selection and characteristics of the participations, data collection and process of analysis. Transferability has also been increased by establishing arguments for the interpretations and by using quotations in the findings (Graneheim \& Lundman, 2004). Our findings have a rich content and are in concordance with other studies on simulation, and ought to be transferred to nursing education and health care organizations.

\section{Conclusion}

Learning in HFS is facilitated if the students' are personally motivated with a positive mindset and have the courage to perform and enter into the unknown. Overcoming reluctance, is therefore a mutual challenge for the teachers and the students. Learning is depended on personal insight, one's ability to reflect on knowledge, and attitude to use HFS as a tool for learning. The ability to enter into the scenario can change and develop with repeated exercises, therefore, early introduction and repeated simulation incorporated into the curriculum is necessary. Nurse educators are challenged to prepare nursing students to practice in complex and changing healthcare environments (Darcy Mahoney, Hancock, Iorianni-Cimbak \& Curley 2013). Therefore, educators need to be aware of nursing students' hindrances during the simulation. The process of adaption and 
incorporating HFS in curriculum requires involvement and strategies shared by all levels in the nursing education. The nursing educators' organizational culture shapes the adoption and incorporation of simulation into nursing curricula (Taplay et al., 2014). Hence, not only students own norms and values influences HFS, but also the own organizations attitudes and beliefs.

HFS are a way to learn using all the senses and a push forward in the transitional process from students to registered nurses. Nursing students need to train to use all senses to develop a clinical glance; this is not something that automatically is used. Adjusted and complex simulation scenarios are a tool for patient safe training for nursing students. By using HFS with a positive mindset, nursing students can improve their ability to perform clinical judgments and faculty teachers can find gaps and strengths in the students' professional development.

\section{Acknowledgements}

The authors would like to thank all the nursing students and the faculty teachers of this research, for their cooperation and willingness to participate in the study.

\section{Authors' Contribution}

All authors designed the work towards submission of this article, contributed to data collection, interpretation and writing of the manuscript, and approved the final version for submission.

\section{Competing Interests Statement}

We declare no conflicts of interests.

\section{References}

Andresen, L., Boud, D., \& Cohen, R. (2000), Experience-based learning. Understanding adult education and training, 2: p. 225-239.

Cantrell, M. L., Meyer, L., \& Mosack, V. (2017). Effects on students simulation Stress. Journal of Nursing Education, 56(3), 139-144. https://doi.org/10.3928/01484834-20170222-04

Darcy Mahoney, A. E., Hancock, L. E., Iorianni-Cimbak, A., \& Curley, M. A. Q. (2013). Using high-fidelity simulation to bridge clinical and classroom learning in undergraduate pediatric nursing. Nurse education today, 33(6), 648-654. https://doi.org/10.1016/j.nedt.2012.01.005

Devlin, M. (2002). Taking Responsibility for Learning isn't Everything: A case for developing tertiary students' conceptions of learning. Teaching in Higher Education, 7(2), 125-138. https://doi.org/10.1080/13562510220124231

Dieckmann, P., Gaba, D., \& Rall, M. (2007). Deepening the theoretical foundations of patient simulation as social practice. Simulation in Healthcare, 2(3), 183-193. https://doi.org/10.1097/SIH.0b013e3180f637f5

Ellström, P. E. (2001). Integrating learning and work: Problems and prospects. Human resource development quarterly, 12(4), 421-435. https://doi.org/10.1002/hrdq.1006

Fitzgerald, C., Kantrowitz-Gordon, I., Katz, J., \& Hirsch, A. (2011). Advanced practice nursing education: challenges and strategies. Nursing research and practice, 2012. https://doi.org/10.1155/2012/854918

Forslund Frykedal, K., \& Samuelsson, M. (2016). "What's in it for Me?" A Study on Students' Accommodation or Resistance during Group Work. Scandinavian Journal of Educational Research, 60(5), 500-514. https://doi.org/10.1080/00313831.2015.1024735

Garrett, B. M., MacPhee, M., \& Jackson, C. (2011). Implementing high-fidelity simulation in Canada: reflections on 3years of practice. Nurse Education Today, 31(7), 671-676. https://doi.org/10.1016/j.nedt.2010.10.028

Garrett, B., MacPhee, M., \& Jackson, C. (2010). High - Fidelity Patient Simulation: Considerations for Effective Learning. Nursing Education Perspectives, 31(5), 309-313.

Gates, M. G., Parr, M. B., \& Hughen, J. E. (2012). Enhancing nursing knowledge using high-fidelity simulation. Journal of Nursing Education, 51(1), 9-15. https://doi.org/10.3928/01484834-20111116-0

Graneheim, U. H., \& Lundman, B. (2004). Qualitative content analysis in nursing research: concepts, procedures and measures to achieve trustworthiness. Nurse education today, 24(2), 105-112. https://doi.org/10.1016/j.nedt.2003.10.001

Guhde, J. (2010). Using Online Exercises and Patient Simulation to Improve Students' Clinical Decision - Making. Nursing Education Perspectives, 31(6), 387-389. 
Hallin, K., Bäckström, B., Häggström, M., \& Kristiansen, L. (2016). High-fidelity simulation: Assessment of student nurses' team achievements of clinical judgment. Nurse Education in Practice, 19, 12-18. https://doi.org/10.1016/j.nepr.2016.03.010

Hallin, K., Häggström, M., Bäckström, B., \& Kristiansen, L. P. (2016). Correlations between clinical judgement and learning style preferences of nursing students in the simulation room. Global journal of health science, 8(6), 1. https://doi.org/10.5539/gjhs.v8n6p1

Henneman, E. A., \& Cunningham, H. (2005). Using clinical simulation to teach patient safety in an acute/critical care nursing course. Nurse Educator, 30(4), 172-177. https://doi.org/10.1097/00006223-200507000-00010

Illeris, K. (2013). Kompetens: [vad, varför, hur]. Competence: (what, why,how). Lund: Studentlitteratur AB.

Kolb, D. A. (2014). Experiential learning: Experience as the source of learning and development. FT press.

Kristiansen, L., Häggström, M., Hallin, K., Andersson, I., \& Bäckström, B. (2015). Svensk översättning, kvalitativ relevansvärdering och kvantitativ reliabilitetstestning av Lasater Clinical Judgment Rubric Swedish translation, qualitative relevance evaluation and quantitative reliability test of Lasater Clinical Judgment Rubric. Nordic Journal of Nursing Research, 35(2), 113-122. https://doi.org/10.1177/0107408315578397

Krueger, R. A., \& Casey, M. A. (2014). Focus groups: A practical guide for applied research. Sage publications.

Lasater, K. (2007). High-fidelity simulation and the development of clinical judgment: Students' experiences. Journal of Nursing Education, 46(6).

Leigh, G. T. (2008). High-fidelity patient simulation and nursing students' self-efficacy: A review of the literature. International Journal of Nursing Education Scholarship, 5(1), 1-17. https://doi.org/10.2202/1548-923X.1613

Levett-Jones, T., Lapkin, S., Hoffman, K., Arthur, C., \& Roche, J. (2011). Examining the impact of high and medium fidelity simulation experiences on nursing students' knowledge acquisition. Nurse education in practice, 11(6), 380-383. https://doi.org/10.1016/j.nepr.2011.03.014

McCaughey, C. S., \& Traynor, M. K. (2010). The role of simulation in nurse education. Nurse Education Today, 30(8), 827-832. https://doi.org/10.1016/j.nedt.2010.03.005

McCutcheon, H. H., \& Pincombe, J. (2001). Intuition: an important tool in the practice of nursing. Journal of Advanced Nursing, 35(3), 342-8. https://doi.org/10.1046/j.1365-2648.2001.01882.x

McGaughey, J. (2009). Acute care teaching in the undergraduate nursing curriculum. Nursing in critical care, 14(1), 11-16. https://doi.org/10.1111/j.1478-5153.2008.00303.x

Moreland, S. S., Lemieux, M. L., \& Myers, A. (2012). End-of-life care and the use of simulation in a baccalaureate nursing program. Int J Nurs Educ Scholarsh, 9(1), 1-16. https://doi.org/10.1097/CNJ.0000000000000338

Mould, J., White, H., \& Gallagher. R (2011). Evaluation of a critical care simulation series for undergraduate nursing students. Contemporary nurse, 38(1-2), 180-190. https://doi.org/10.5172/conu.2011.38.1-2.180

Nehring, W. M., \& Lashley, F. R., (2010). High-fidelity patient simulation in nursing education. Jones \& Bartlett Publishers.

Nielsen, B., \& Harder, N. (2013). Causes of Student Anxiety during Simulation:What the Literature Says. Clinical Simulation in Nursing. 9, e507-e512. https://doi.org/10.1515/ijnes-2015-0010

Passarelli, A. M., \& Kolb, D. A. (2011). The Learning Way: Learning from Experience as the Path to Lifelong. The Oxford Handbook of Lifelong Learning, 70.

Patton, M. Q. (1990). Qualitative evaluation and research methods. SAGE Publications, inc.

Pennbrant, S., Nilsson, M. S., Öhlén, J., \& Rudman, A. (2013). Mastering the professional role as a newly graduated registered nurse. Nurse education today, 33(7), 739-745. https://doi.org/10.1016/j.nedt.2012.11.021

Pilhammar, E. (2011). Erfarenhetsbaserad kunskap \& lärande inom vård \& medicin. Lund: Studentlitteratur.

Reid-Searl, K., Happell, B., Vieth, L., \& Eaton, A. (2012). High fidelity patient silicone simulation: A qualitative evaluation of nursing students' experiences. Collegian, 19(2), 77-83. https://doi.org/10.1016/j.colegn.2011.09.003

Taplay, K., Jack, S. M., Baxter, P., Eva, K., \& Martin, L. (2014). Organizational Culture Shapes the Adoption and Incorporation of Simulation into Nursing Curricula: A Grounded Theory Study. Nursing Research and 
Practice, 12 . https://doi.org/10.1155/2014/197591

Traynor, M., Gallagher, A., Martin, L., \& Smyth, S. (2010). From novice to expert: using simulators to enhance practical skill. British Journal of Nursing, 19(22), 1422. https://doi.org/10.12968/bjon.2010.19.22.1422

Waldner, M. H., \& Olson, J. K. (2007). Taking the patient to the classroom: Applying theoretical frameworks to simulation in nursing education. International Journal of Nursing Education Scholarship, 4(1). https://doi.org/10.2202/1548-923X.1317

Wotton, K., Davis, J., Button, D., \& Kelton, M. (2010). Third-year undergraduate nursing students' perceptions of high-fidelity simulation. The Journal of nursing education, 49(11), 632-639. https://doi.org/10.3928/01484834-20100831-01

\section{Copyrights}

Copyright for this article is retained by the author(s), with first publication rights granted to the journal.

This is an open-access article distributed under the terms and conditions of the Creative Commons Attribution license (http://creativecommons.org/licenses/by/4.0/). 